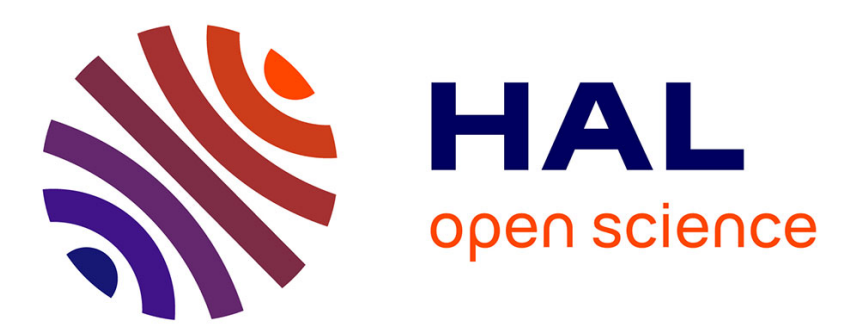

\title{
XAS Study of the High Pressure Behaviour of Quartz-Like Compounds
}

J. Badro, J. Itié, A. Polian, P. Gillet

\section{To cite this version:}

J. Badro, J. Itié, A. Polian, P. Gillet. XAS Study of the High Pressure Behaviour of Quartz-Like Compounds. Journal de Physique IV Proceedings, 1997, 7 (C2), pp.C2-987-C2-989. 10.1051/jp4:19972109 . jpa-00255166

\section{HAL Id: jpa-00255166 https://hal.science/jpa-00255166}

Submitted on 1 Jan 1997

HAL is a multi-disciplinary open access archive for the deposit and dissemination of scientific research documents, whether they are published or not. The documents may come from teaching and research institutions in France or abroad, or from public or private research centers.
L'archive ouverte pluridisciplinaire HAL, est destinée au dépôt et à la diffusion de documents scientifiques de niveau recherche, publiés ou non, émanant des établissements d'enseignement et de recherche français ou étrangers, des laboratoires publics ou privés. 


\title{
XAS Study of the High Pressure Behaviour of Quartz-Like Compounds
}

\author{
J. Badro***, J.P. Itié**, A. Polian** and P. Gillet***** \\ * Laboratoire de Sciences de la Terre, École Normale Supérieure de Lyon, 46 allée d'Italie, \\ 69364 Lyon cedex 07, France \\ ** Laboratoire de Physique des Milieux Condensés, Université Pierre et Marie Curie (Paris VI), \\ 4 place Jussieu, BP. 77, 75252 Paris cedex 05, France \\ *** also at Institut Universitaire de France
}

\begin{abstract}
EXAFS spectroscopy experiments have been carried out on quartz-like $\alpha-\mathrm{GaAsO}_{4}$ and $\alpha$-AlAsO $\mathrm{O}_{4}$ at high pressure and room temperature. It has been shown that these materials exhibit two structural phase transitions; the first transition to a high pressure crystalline form occurs at $9 \mathrm{GPa}$ and is reversible upon decompression, whereas the second transition occurrs at higher pressures and is irreversible. In $\alpha-\mathrm{GaAsO}_{4}$, EXAFS measurements agree with the predicted transition from four- to sixfold coordination of oxygen atoms around the cations, but the two local coordination transformations are not dissociated; in fact, both $\mathrm{As}$ and $\mathrm{Ga}$ atoms exhibit a coordination change at the onset of the first phase transition, the rate of transformation being significantly higher for $\mathrm{Ga}$ atoms. In both cases, the average bond length increases very rapidly with pressure thus yielding the first compression stage after the transition. In the second stage, the average bond lengths increase slowly, ultimately reaching six-fold coordination above $28 \mathrm{GPa}$ and $24 \mathrm{GPa}$ for As and $\mathrm{Ga}$ respectively. The behaviour of the As $\mathrm{K}$-edge EXAFS is the same for both compounds, and enables us to link the behaviour of $\mathrm{Ga}$ and $\mathrm{Al}$ atoms. The local transformations are well described and a direct link with phosphate berlinites seems timely.
\end{abstract}

\section{Introduction}

Quartz and quartz-like compounds are among nature's most interesting minerals, because their various structures in different regions of thermodynamic phase space are simple yet common ones. The low pressure polymorphs consist of tetrahedrally coordinated cations whereas the higher pressures forms have octahedral cation arrangements, in which oxygen atoms are packed in a body-centred cubic (bcc) sublattice around the cations. At room temperature, the kinetics of these fourto six-coordinated transitions are very slow leading to a pressure-induced amorphization (PIA) process in quartz. This phenomenon has been observed by different probes $^{i-4}$ on the $\mathrm{SiO}_{2}$ system. The room temperature compression and PIA of isostructural $\alpha-\mathrm{GeO}_{2}$ has also been studied by X-ray diffraction and EXAFS spectroscopy ${ }^{5}$ and the study has shown that germanium coordination increases from four to six through the crystal-to-amorphous transition. Molecular dynamics (MD) simulations $^{6-10}$ have shown that changes in the local structure during the transition in quartz are very similar to those observed in $\mathrm{GeO}_{2}$.

In quartz-like berlinites, it was first thought that $\alpha-\mathrm{AlPO}_{4}$ exhibited the same room temperature and high pressure behaviour as quart $z^{11}$, and underwent PIA at $15 \mathrm{GPa}$. A later Raman scattering study ${ }^{12}$ as well as Brillouin spectroscopy measurements $^{13}$ have shown that this transition is not a PIA, but a polymorphic crystalline phase transition, the high pressure form being very poorly crystallized, and therefore yielding very poor X-ray diffraction patterns. MD simulations associate the transition with a destabilization of the $\mathrm{AlO}_{4}$ tetrahedron and its transition towards an $\mathrm{AlO}_{6}$ octahedron; they also have concluded that PIA would occur only when the $\mathrm{PO}_{4}$ tetrahedra became unstable, at a predicted pressure of $80 \mathrm{GPa}$, which has not yet been produced experimentally using $\mathrm{AlPO}_{4}$. In-situ EXAFS experiments were performed ${ }^{\mathrm{in}}$ on an isostructural compound, $\mathrm{GaPO}_{4}$, at the $\mathrm{Ga} \mathrm{K}$-edge, and the polymorphic phase transition observed at $12 \mathrm{GPa}$ is associated with a four- to six-fold oxygen coordination change around gallium atoms.

\section{Experimental}

Quartz-structured aluminium and gallium arsenate powders were used for this high pressure dispersive EXAFS study. The samples were loaded in a stainless steel inconel gasket with a $250 \mu \mathrm{m}$ hole diameter and $50 \mu \mathrm{m}$ thickness and high pressures were generated by a membrane driven diamond anvil cell (DAC). Silicon oil was used as a pressure transmitting medium, and ruby fluorescence was used as a pressure gauge. The measurements were carried out on the D-11 dispersive ${ }^{15,16}$ EXAFS beamline on the DCI storage ring of the LURE synchrotron facility in Orsay, France. Each absorption measurement was accumulated for 32 times and 3.5 seconds each, and was followed by the collection of a spectrum of a GaAs sample in order to insure edge energy stability. 


\section{Results and Discussion}

\section{1. $\mathrm{GaAsO}_{4}$}

EXAFS spectra at the $\mathrm{Ga}$ and As K-edges show a very interesting pattern with increasing pressure (fig. I); a first polymorphic transition ${ }^{17}$ occurs around $9 \mathrm{GPa}$ and is observed for both $\mathrm{Ga}$ and As. The average Ga-O distance rises rapidely and then levels off above $12 \mathrm{GPa}$ corresponding to an octahedral arrangement of gallium atoms. Meanwhile, the As-O mean distance also increases between 9 and $12 \mathrm{GPa}$ at which point another compression regime appears and the As-O bond lengthens in a slower manner, until a plateau is reached at about $25 \mathrm{GPa}$. These distance variations are related to the rate of transformation from 4-fold to 6-fold coordinated cations; the arsenic atoms have two transformation regimes, the second being much slower because the six-coordinated structure of gallium atoms renders the system less compressible. This would therefore imply that the coordination of both $\mathrm{As}$ and $\mathrm{Ga}$ atoms transform at $9 \mathrm{GPa}$, and that the Ga 4-to-6 transformation is faster, permitting the As 4-to-6 transformation to continue up to $25 \mathrm{GPa}$. At this pressure, the system consists of a pseudorutile type structure, the XANES spectra for As and Ga atoms being very similar to the XANES spectrum of GeO 2 at high pressure ${ }^{5}$. A recent X-ray diffraction study ${ }^{18}$ by Clark et al. has shown that the intermediate crystalline phase can be indexed in a triclinic (yet very close to orthorhombic) structure. It was pointed out that this phase has $2 / 3$ of the cations in 6-fold coordination and the rest in 4-fold. Our EXAFS measurements concur with this result and it can be added that in this particular case, all $\mathrm{Ga}$ atoms are in six-fold coordination whereas a smaller portion of As atoms are in octahedral coordination.

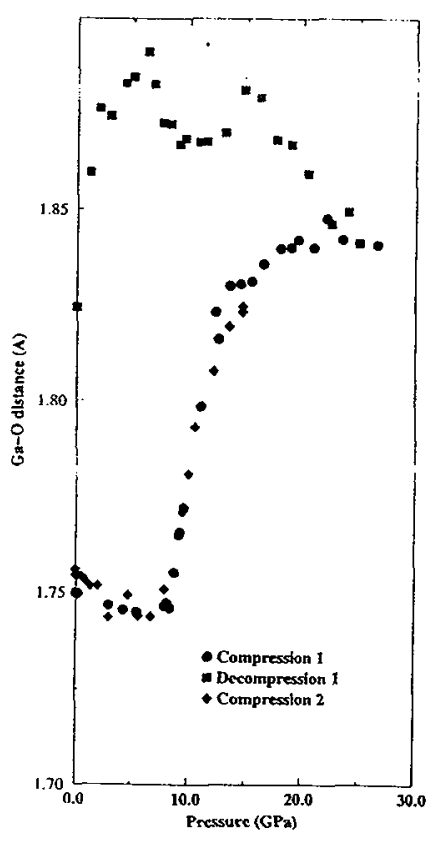

Figure la: Ga-O average distance from Ga K-edge EXAFS on $\mathrm{GaAsO} 4$ as a function of pressure

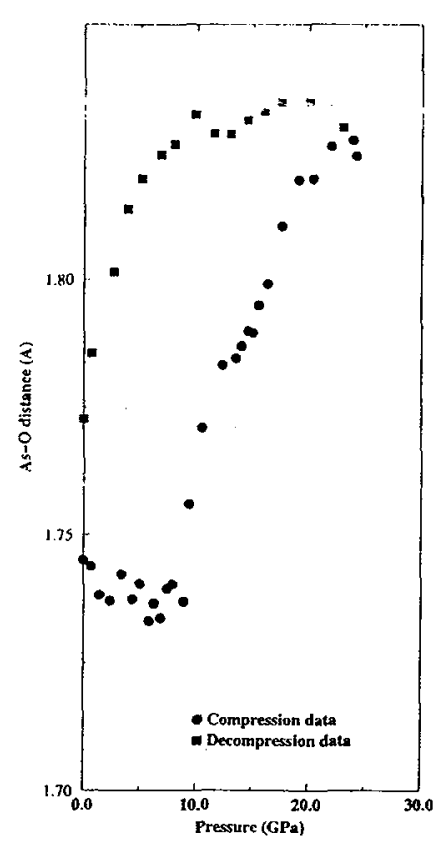

Figure $1 \mathrm{~b}: \mathrm{As}-\mathrm{O}$ average distance from As K-edge EXAFS on $\mathrm{GaAsO} 4$ as a function of pressure

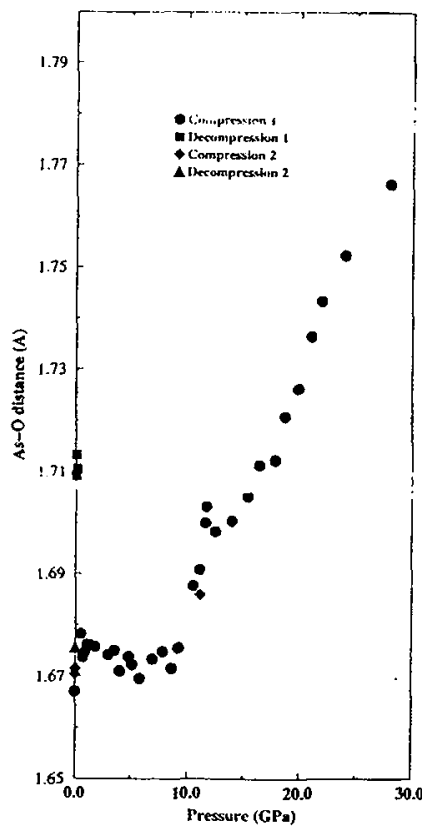

Figure 2: As-O average distance from As K-edge EXAFS on AlAsO4 as a function of pressure

In a $\mathrm{GaAsO}_{4}$ sample quenched from $15 \mathrm{GPa}$, after all $\mathrm{Ga}$ atoms have become six-fold coordinated and before all As clusters turn into octahedra, the $\mathrm{Ga}$ atoms undergo a back-transformation to a tetrahedral arrangement with partial amorphization of the sample, whereas the sample decompressed from $25 \mathrm{GPa}$ has a much more complex history and shows amorphous character after decompression, mainly consisting of octahedral configurations. 


\section{2. $\mathrm{AlAsO}_{4}$}

A recent X-ray diffraction study ${ }^{19}$ has shown that $\mathrm{AlAsO}_{4}$ undergoes a crystal-to-crystal phase transition between 7.6 and $8.4 \mathrm{GPa}$. This study also claimed that the high pressure crystalline phase undergoes PIA between 8.4 and 9.4 GPa. Our $\mathrm{X}$-ray diffraction and Raman scattering experiments disagree with these conclusions. In fact, Raman scattering on single crystals as well as X-ray powder diffraction clearly agree with the first crystal-to-crystal transition between 8.5 and $9.5 \mathrm{GPa}$, but crystalline reflections of the high pressure phase are observed up to $35 \mathrm{GPa}$ and Raman spectra show new crystalline features between 9.6 and $13.3 \mathrm{GPa}$.

The As K-edge EXAFS show a rapid increase in As coordination between 9 and $12 \mathrm{GPa}$ (fig. 2) followed by a lightly less rapid rise in As-O distance up to $28 \mathrm{GPa}$, exactly as seen in $\mathrm{GaAsO}_{4}$. A direct comparison with $\mathrm{GaAsO}_{4}$ in which both cations can be monitored by in-situ EXAFS, would imply that Al coordination should rise rapidly from 4 to 6 and should level off at about $12 \mathrm{GPa}$ at which point only As coordination increases ultimately reaching a value of 6 . Upon decompression, the transition is reversible below $13 \mathrm{GPa}$ and becomes irreversible above this pressure.

\section{Conclusions}

We have shown that both aluminium and gallium arsenate undergo two phase transitions at high pressure and $300 \mathrm{~K}$. The first transformation is a crystalline polymorphic phase transition and is associated, as opposed to phosphates ${ }^{17}$, with a local transition from four- to six-fold coordination of both cations. The second transition occurs over a large pressure domain, for it is not a usual first order transformation, but a PIA, and starts slightly above the point where one of the cations reaches complete six-fold coordination. As with quartz, samples decompressed from these pressure domains are more or less amorphous, depending on the maximum pressure reached. The first transition is locally reversible yet producing some amorphous material, whereas the second transition leading to a 'pressure glass' is not.

The destabilization of tetrahedral clusters in both $\mathrm{GaAsO}_{4}$ and $\mathrm{AlAsO}_{4}$ has been demonstrated by in-situ EXAFS, and is in good agreement with $\mathrm{MD}$ studies on berlinite. Experimental and numerical studies are converging on the reversibility of the first transition; the remaining tetrahedral clusters $\left(\mathrm{PO}_{4}\right.$ for phosphates, and $\mathrm{AsO}_{4}$ for arsenates) seem to form an undeformed sublattice that forces the transformed octahedra back into their original positions when pressure is released. In the case of arsenates, if these strong clusters are transformed into octahedra, the back-transformation is not possible for the driving force has vanished, and the systems becomes amorphous. In the case of phosphates, the critical pressure needed to destabilize the $\mathrm{PO}_{4}$ tetrahedra has not yet been reached.

\section{References}

[1] R.J. Hemley, A.P. Jephcoat, H.K. Mao, L.C. Ming and M.H. Manghani, Nature 334 (1988) 52-54

[2] K.J Kingma, C. Meade, R.J. Hemley, H.K. Mao and D.R. Veblen, Science 259 (1993) 666-669

[3] R.M. Hazen, L.W. Finger, R.J. Hemley and H.K. Mao, Solid State Comm. 72 (1989) 507-511

[4] Q. Williams, R.J. Hemley, M.B. Kruger and R. Jeanloz, J. Geophys. Res. 98 (1993) 22157-22170

[5] J.-P. Itié, A. Polian, G. Calas, J. Petiau, A. Fontaine and H. Tolentino, Phys. Rev. Let. 63 (1989) 398-401

[6] J.S. Tse and D.D. Klug, Phys. Rev. Let. 67 (1991) 3559-3562

[7] J.R. Chelikowsky, H.E. King, N. Troullier, J.L. Martins and J. Glinnemann, Phys. Rev. Let. 65 (1990) $3309-3312$

[8] N. Binggeli, J.R. Chelikowsky, Nature 353 (1991) 344-346

[9] G.W. Watson and S.C. Parker, Phys. Rev. B 52 (1995) 13306-13309

[10] J. Badro, J.-L. Barrat and Ph. Gillet, Phys. Rev. Lett. 76 (1996) 772-775

[11] M.B. Kruger and R. Jeanloz, Science 249 (1990) 647-649

[12] Ph. Gillet, J. Badro, B. Varrel and P.F. McMillan, Phys. Rev. B 51 (1995) 11262-11269

[13] A. Polian, M. Grimsditch and E. Philippot, Phys. Rev. Lett. 71 (1993) 3143-3145

[14] J.-P. Itie, this conference

[15] E. Dartyges, C. Depautex, J.M. Dubuisson, A. Fontaine, A. Jucha, P. Leboucher and G. Tourillon, Nucl. Inst. Meth. A246 (1986) pp.456

[16] H. Tolentino, E. Dartyges, A. Fontaine and G. Tourillon, J. Appl. Phys. 21 (1988) pp.15

[17] J.-P. Itié, T. Tinoco, A. Polian, G. Demazeau, S. Matar and E. Philippot, High Pressure Research 14 (1996) 269-276

[18] S.M. Clark, A.G. Christy, R. Jones, J. Chen, J.M. Thomas and G.N. Greaves, Phys. Rev. B 51 (1995) 38-51

[19] H. Sowa and H. Ahsbahs, Zeit. fitr Krist. 211 (1996) 96-100 